\title{
PENGEMBANGAN SOFTSKILL MAHASISWA CALON GURU MELALUI PEMBERDAYAAN UNIT KEGIATAN MAHASISWA DI UNIVERSITAS PASUNDAN
}

\author{
Cartono, Ida Yayu N. Hizqiyah, Fitri Aryanti \\ Program Studi Pendidikan Biologi, Universitas Pasundan Bandung \\ email : fitriaryanti@unpas.ac.id
}

\begin{abstract}
Abstrak
Soft skills merupakan bagian keterampilan dari seseorang yang lebih bersifat pada kehalusan atau sensitifitas perasaan seseorang terhadap lingkungan di sekitarnya Soft skills menjadi suatu hal yang sangat penting karena kesuksesan seseorang tidak hanya ditentukan oleh pengetahuan dan kemampuan teknis (hard skills) saja, tetapi yang lebih utama didukung oleh kemampuan mengelola diri dan orang lain (soft skills). Tujuan dari penelitian ini yaitu untuk menganalisis kegiatan UKM dan kegiatan perkuliahan dalam aktivitas presentasi yang berkaitan dengan pengembangan soft skills mahasiswa calon guru. Metode penelitian ini merupakan penelitian deskriptif kualitatif dengan teknik analisis deskriptif kualitatif. Hasil penelitian menunjukkan bahwa program kerja Unit Kegiatan Mahasiswa dan proses perkuliahan pada aktivitas diskusi mahasiswa mulai menerapkan aspek-aspek soft skills. Aspek soft skills yang dijaring terdiri dari beberapa aspek yaitu kemampuan berkomunikasi, kemampuan berfikir atau bernalar, kemampuan menyelesaikan masalah, kerjasama tim, etika/moral dan keterampilan kepemimpinan.
\end{abstract}

Keywords: Soft Skills, Unit Kegiatan Mahasiswa

\section{DEVELOPMENT OF STUDENT SOFTSKILL THROUGH STUDENT ACTIVITY UNIT AT PASUNDAN UNIVERSITY}

\author{
Cartono, Ida Yayu N. Hizqiyah, Fitri Aryanti \\ Departement of Biology Education, Pasundan University \\ email : fitriaryanti@unpas.ac.id
}

\begin{abstract}
Soft skills are a skill part of someone who is more of a refinement or sensitivity of a person's feelings towards the surrounding environment Soft skills become a very important thing because a person's success is not only determined by the knowledge and technical skills (hard skills), but more importantly supported by the ability to manage themselves and others (soft skills). The purpose of this study is to analyze the activities of SMEs and lectures activities in presentation activities related to the soft skills development of prospective teachers. This research method is descriptive qualitative research with qualitative descriptive analysis technique. The results showed that the work program of Student Activity Unit and lecture process on student discussion activity began to apply the soft skills aspects. The soft skills aspect that is encompassed consists of several aspects, namely communication ability, thinking ability or reasoning, problem solving skills, teamwork, ethics / moral and leadership skills.
\end{abstract}

Keywords: Soft Skills, Student Activity Unit 


\section{PENDAHULUAN}

Lembaga pendidikan mempunyai kewajiban untuk merancang dan melaksanakan pendidikan sehingga mampu melahirkan generasi muda masa depan yang siap menghadapi segala situasi dan kondisi serta memiliki daya saing yang tinggi.

Oleh karena itu, berbagai cara berusaha untuk meningkatkan perkembangan pendidikan untuk mencerdaskan kehidupan bangsa dan negara. Pendidikan yang diperoleh mahasiswa calon guru tidak hanya didapatkan di dalam kelas, kegiatan di luar kelas seperti kegiatan ekstrakurikuler yang berisikan materi di luar perkuliahan sangat bermanfaat dalam pengembangan potensi mahasiswa. Ekstrakurikuler di lingkungan kampus atau Unit Kegiatan Mahasiswa (UKM) sangat didukung oleh pihak universitas, sehingga keberadaan UKM tersebut dapat membantu mahasiswa dalam belajar bersosialisasi, mengembangkan minat dan bakat, menambah pengetahuan, menambah wawasan, belajar berorganisasi, belajar berkomunikasi dan memecahkan masalah. Keaktifan mahasiswa dalam perkuliahan dan kegiatan ekstrakurikuler selain dapat meningkatkan aspek hard skills juga dapat mengasah soft skills mahasiswa.

Mahasiswa calon guru selain memiliki ilmu pengetahuan juga harus mempunyai kemampuan soft skills. Seorang guru pada abad 21 dan abad selanjutnya ditantang untuk melakukan akselerasi terhadap perkembangan informasi dan komunikasi. Pembelajaran di kelas dan pengelolaan kelas, pada abad ini harus disesuaikan dengan standar kemajuan teknologi informasi dan komunikasi. Menurut Yahya dalam Cahyono (2012) memaparkan bahwa tantangan seorang pendidik diabad 21 yaitu pendidikan yang berfokus pada character building, pendidikan yang peduli perubahan iklim, enterprenual mindset, membangun learning community, kekuatan bersaing bukan lagi kepandaian tetapi kreativitas dan kecerdasan bertindak (hard skills- soft skills).

Perkembangan soft skills pada setiap individu berbeda-beda karena soft skills merupakan hasil interaksi dan komunikasi dalam kehidupan bermasyarakat. Soft skills tidak di peroleh dalam mata kuliah khusus, tetapi dapat di latih secara intensif dalam setiap pembelajaran. Peranan soft skills itu sendiri dapat membentuk keterampilan seseorang dalam mengelola diri sendiri dan orang lain sehingga terjalin hubungan yang sangat baik, seperti yang diungkapkan oleh para peneliti di Harvard University dalam Rismansyah (2015) yang menyatakan bahwa kesuksesan hanya ditentukan sekitar $20 \%$ dengan hard skills dan sisanya $80 \%$ dengan soft skills, sehingga hard skills dan soft skills harus terintegrasi dengan baik dimana hard skills bisa diperoleh di dunia pendidikan formal sedangkan soft skills diperoleh bisa melalui pendidikan formal dan di luar pendidikan formal. 


\section{METODE PENELITIAN}

Penelitian ini merupakan penelitian deskriptif kualitatif yang dilakukan terhadap mahasiswa calon guru untuk mengetahui profil soft skills mahasiswa melalui UKM dan proses perkuliahan melalui aktivitas presentasi di kelas. Sampel penelitian adalah mahasiswa calon guru sebanyak 40 orang mahasiswa. Peneliti tidak memberikan treatment tetapi hanya berusaha untuk mengungkap data berdasarnya hasil survey. Instrumen yang digunakan adalah angket dan lembar observasi kegiatan diskusi dan presentasi serta panduan wawancara.

\section{HASIL DAN PEMBAHASAN}

Berdasarkan hasil survey terdapat beberapa mahasiswa calon guru yang aktif di UKM seperti di DKM dan KSR. Peneliti mengidentifikasi program kerja setiap UKM yang berkaitan dengan pengembangan soft skills mahasiswa. Aspek soft skills mahasiswa yang akan dijaring yaitu kemampuan berkomunikasi, kemampuan berfikir atau bernalar, kemampuan menyelesaikan masalah, kerjasama tim, etika dan keterampilan kepemimpinan. Hasil identifikasi program kerja UKM dalam pengembangan soft skills mahasiswa terdapat pada Tabel.1.

Tabel.1. Hasil Identifikasi Program Kerja UKM

\begin{tabular}{|c|c|c|c|}
\hline UKM & & Program Kerja & Aspek Soft Skills yang Dijaring \\
\hline DKM & 4. & 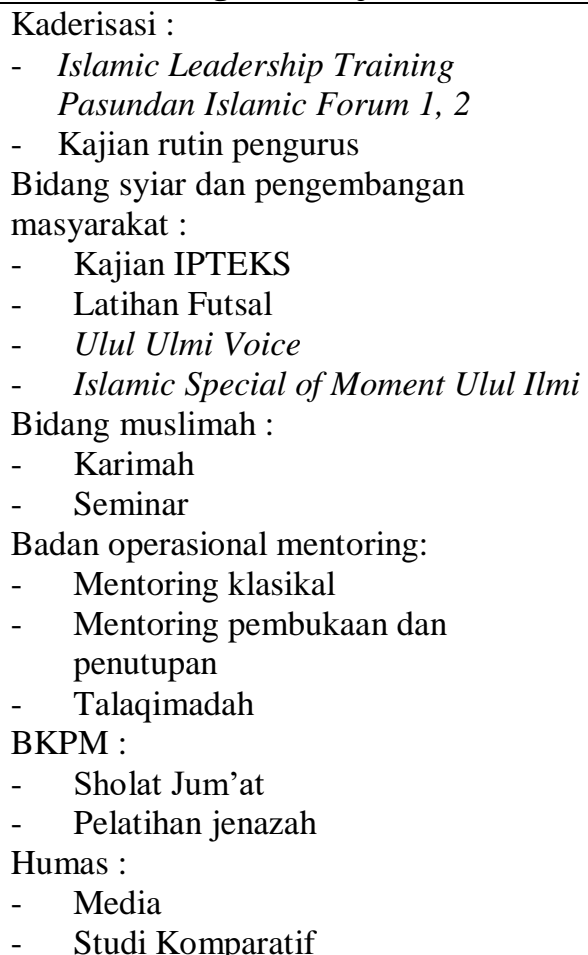 & $\begin{array}{l}\text { Kemampuan berkomunikasi pada semua } \\
\text { bidang program kerja; } \\
\text { - Kemampuan berfikir atau bernalar pada } \\
\text { program kerja bidang kaderisasi, bidang } \\
\text { syiar dan pengembangan masyarakat, } \\
\text { bidang muslimah; } \\
\text { - Kemampuan menyelesaikan masalah } \\
\text { pada semua bidang program kerja; } \\
\text { - Kemampuan kerjasama tim pada semua } \\
\text { bidang program kerja; } \\
\text { - Kemampuan etika/moral pada semua } \\
\text { bidang program kerja; } \\
\text { - Keterampilan kepemimpinan pada } \\
\text { bidang kaderisasi,, bidang syiar dan } \\
\text { pengembangan masyarakat, bidang } \\
\text { muslimah. }\end{array}$ \\
\hline KSR & $\begin{array}{l}1 . \\
2 . \\
3 . \\
4 . \\
5 .\end{array}$ & $\begin{array}{l}\text { OPMB Universitas } \\
\text { Pradiklat } \\
\text { Diklatsar } \\
\text { Latihan pemantapan (Latap) } \\
\text { Donor darah } \\
\text { Semarak donor darah }\end{array}$ & $\begin{array}{l}\text { - Kemampuan berkomunikasi pada semua } \\
\text { bidang program kerja; } \\
\text { - Kemampuan berfikir atau bernalar pada } \\
\text { program kerja diklatsar, latap; } \\
\text { - Kemampuan menyelesaikan masalah } \\
\text { pada semua bidang program kerja; }\end{array}$ \\
\hline
\end{tabular}




\begin{tabular}{llll}
\hline 7. & Latihan managemen organisasi & $\bullet$ & Kemampuan kerjasama tim pada semua \\
8. & Water Resque & bidang program kerja; \\
9. & Studi banding & Kemampuan etika/moral pada semua \\
10. & Seminar narkoba nasional & Kidang program kerja; \\
11. & Bina masyarakat desa & $\bullet$ & Keterampilan kepemimpinan pada \\
& & $\begin{array}{l}\text { program kerja pradiklat, diklatsar, latap, } \\
\text { bina masyarakat desa. }\end{array}$ \\
\hline
\end{tabular}

Berdasarkan hasil rekap observasi mahasiswa, indikator soft skills diperoleh melalui aktivitas perkuliahan seperti pada aktivitas presentasi kelompok. Perolehan skor soft skills pada setiap aktivitas dapat dilihat pada Tabel.2.

Tabel.2. Rekapitulasi Perolehan Profil Soft Skills Melalui Aktivitas Presentasi Mahasiswa

\begin{tabular}{lll}
\hline \multicolumn{1}{c}{ Indikator Soft Skills } & Skor Mahasiswa & Skor Max \\
\hline Kemampuan Berkomunikasi & 37 & 45 \\
Kemampuan Berfikir atau Bernalar & 24 & 35 \\
Kemampuan Menyelesaikan Masalah & 28 & 40 \\
Kerjasama Tim & 27 & 30 \\
Etika-Moral & 27 & 30 \\
Keterampilan Kepemimpinan & 16 & 20 \\
\hline TOTAL & $\mathbf{1 5 9}$ & $\mathbf{2 0 0}$ \\
\hline
\end{tabular}

Tabel 3. Rekapitulasi Angket Dosen

\begin{tabular}{|c|c|c|c|c|}
\hline Aspek Yang Diamati & $\mathbf{Y a}$ & $\begin{array}{l}\text { Persentase } \\
\quad(\%)\end{array}$ & Tidak & $\begin{array}{c}\text { Persentase } \\
(\%)\end{array}$ \\
\hline Mengaitkan fakta dengan konsep yang dipelajari & 8 & 4.85 & 3 & 1.82 \\
\hline Menyajikan permasalahan yang harus diselesaikan & 9 & 5.45 & 2 & 1.21 \\
\hline $\begin{array}{l}\text { Menggunakan strategi/ model/ pendekata dalam } \\
\text { pemecahan masalah tersebut }\end{array}$ & 10 & 6.06 & 1 & 0.61 \\
\hline $\begin{array}{l}\text { Mentargetkan CPL (soft skill dan hard skill serta } \\
\text { kompetensi lainnya) untuk setiap } \\
\text { pembahasan/pertemuan }\end{array}$ & 10 & 6.06 & 1 & 0.61 \\
\hline $\begin{array}{l}\text { Menggunakan media/model yang sesuai dengan } \\
\text { materi yang dibahas }\end{array}$ & 11 & 6.67 & 0 & 0.00 \\
\hline $\begin{array}{l}\text { Melibatkan mahasiswa untuk menggali keterangan- } \\
\text { keterangan yang ada pada media/model }\end{array}$ & 11 & 6.67 & 0 & 0.00 \\
\hline Menggunakan teknik bertanya yang tepat & 10 & 6.06 & 1 & 0.61 \\
\hline $\begin{array}{l}\text { Melibatkan mahasiswa secara aktif selama } \\
\text { pembelajaran berlangsung }\end{array}$ & 10 & 6.06 & 1 & 0.61 \\
\hline $\begin{array}{l}\text { Menjalin interaksi yang baik antara guru dengan } \\
\text { mahasiswa }\end{array}$ & 11 & 6.67 & 0 & 0.00 \\
\hline $\begin{array}{l}\text { Kedalaman materi yang disampaikan guru sudah } \\
\text { tepat/sesuai }\end{array}$ & 11 & 6.67 & 0 & 0.00 \\
\hline $\begin{array}{l}\text { Memberikan kesempatan pada mahasiswa untuk } \\
\text { mengajukan pertanyaan dan pendapat }\end{array}$ & 11 & 6.67 & 0 & 0.00 \\
\hline
\end{tabular}




\begin{tabular}{lcccc}
\hline $\begin{array}{l}\text { Menjawab pertanyaan mahasiswa dengan tepat dan } \\
\text { jelas }\end{array}$ & 10 & 6.06 & 1 & 0.61 \\
$\begin{array}{l}\text { Menggunakan bahasa yang lebih mudah dipahami } \\
\text { oleh mahasiswa }\end{array}$ & 11 & 6.67 & 0 & 0.00 \\
$\begin{array}{l}\text { Memberikan tindakan pada mahasiswa yang tidak } \\
\text { memperhatikan }\end{array}$ & 11 & 6.67 & 0 & 0.00 \\
Mahasiswa memiliki buku catatan / latihan & 11 & 6.67 & 0 & 0.00 \\
\hline \multicolumn{1}{c}{ TOTAL } & $\mathbf{1 5 5}$ & $\mathbf{9 3 . 9 4}$ & $\mathbf{1 0}$ & $\mathbf{6 . 0 6}$ \\
\hline
\end{tabular}

Berdasarkan tabel 3 menunjukkan bahwa indikator kemampuan berkomunikasi memperoleh skor yang tinggi yaitu 37. Skor indikator soft skills lainnya secara berurutan yaitu kemampuan menyelesaikan masalah 28, skor kerjasama tim etika-moral sebesar 27, skor kemampuan berpikir dan bernalar sebesar 24 dan skor keterampilan kepemimpinan sebesar 16.

Dosen yang telah diwawancarai yaitu dosen yang mengampu mata kuliah Biologi Umum, Embriologi, Agama, Bioteknologi, Evaluasi Hasil Belajar, Ekologi Tumbuhan, Pedagogi, Inovasi Pembelajaran, Bahasa Sunda, Perencanaan, Zoologi Invertebrata. Sebagian diantara dosen-dosen telah mengampu mata kuliah yang sama selama lebih dari 5 tahun, namun sebagian besar masih berganti-ganti mata kuliah disesuaikan dengan kebutuhan dan kondisi pada saat semester berlangsung. Hampir semua dosen tetap mengampu lebih dari satu mata kuliah, minimal satu mata kuliah pada setiap semester.
Berdasarkan Tabel.1. dapat dilihat program kerja setiap UKM pada berbagai bidang. Keberadaan UKM tersebut perlu didukung dan difasilitas oleh pihak kampus, karena potensi pengembangan soft skills dapat tergali sehingga dapat menyalurkan minat, mengasah bakat dan dapat menerapkan teori menjadi praktek. Menurut Herizon dan Wirda (2012) soft skills merupakan kemampuan yang bersifat intangible/tidak dapat dilihat namun sangat dibutuhkan untuk kesuksesan seseorang dalam dunia kerja. Keikutsertaan dalam UKM dapat mengasah perpaduan soft skills dan social skills yang merupakan kemampuan untuk berinteraksi dengan orang lain pada konteks sosial. Menurut Rao (2015) mengungkapkan bahwa dengan melakukan pelatihan soft skills untuk meningkatkan keterampilan kerja pada siswa dan hasil penelitiannya menunjukan bahwa soft skills akan memungkinkan siswa tumbuh sebagai individu yang siap bersaing di dunia kerja dan juga mampu untuk membuka lapangan kerja sendiri.

Berdasarkan hasil analisis tersebut menunjukkan bahwa mengikuti UKM dapat 
memberi manfaat bagi mahasiswa. Seorang mahasiswa lebih baik menyeimbangkan kehidupannya dalam bidang akademik dan non akademik. Beberapa manfaat mengikuti UKM menurut Ikhsania (2013) yaitu melatih leadership skill, menyalurkan hobi dan minat, networking atau memperluas jaringan, dan belajar manajemen waktu.

Suharyanti,

$\mathrm{dkk}$

(2015) mengungkapkan bahwa dunia kerja membutuhkan orang-orang yang tidak hanya lulus dengan nilai yang tinggi tetapi mereka butuh kemampuan berkomunikasi, integritas dan kemampuan bekerjasama dengan orang lain. Berdasarkan hal tersebut, maka jelas bahwa peningkatan Sumber Daya Manusia (SDM) sebaiknya diperoleh melalui peningkatan kemampuan soft skills termasuk pada jalur pendidikan yang diterapkan di Indonesia. Setiap mahasiswa sudah mempunyai soft skills yang berbeda-beda, dan hal tersebut dapat dikembangkan melalui pembelajaran di kelas atau melalui kegiatan kemahasiswaan.

Berdasarkan Tabel.2. aktivitas presentasi yang dilakukan pada perkuliahan dapat membantu mahasiswa dalam melatih kemampuan berkomunikasi. Manfaat aktivitas presentasi menurut Sulaiman (2015) yaitu wawasan semakin luas, meningkatkan kemampuan berpikir kritis, meningkatkan kemampuan memimpin, mengatasi rasa takut untuk berbicara di depan umum dan memperluas jaringan. Menurut Rahayu (2013) presentasi merupakan kegiatan yang penting dalam mengkomunikasikan suatu gagasan kepada orang lain dengan berbagai tujuan. Kegiatan presentasi dapat didukung dengan penggunaan multimedia. Setiawan, dkk (2016) mengungkapkan bahwa pengembangan soft skills pada siswa dapat dipenuhi melalui model pembelajaran multimedia berbasis Teknologi Informasi Komunikasi (TIK) melalui 3 metode yaitu metode presentasi dengan Microsoft Power Point dan Wondershare, metode demonstrasi melalui pengoperasionalisasian program dan metode praktik dengan pembuatan media pembelajaran secara langsung oleh peserta dengan pemanfaatan program-program tersebut.

Berdasarkan hasil rekapitulasi angket dosen mengenai kegiatan perkuliahan menunjukkan bahwa sebagian besar dosen (72\%) sudah melaksanakan aspek-aspek yang ada dalam angket tersebut. Aspekaspek tersebut sudah menjadi suatu rutinitas yang harus dilakukan oleh setiap dosen berdasarkan RPS yang disusun sebelum mata kuliah tersebut dilaksanakan dengan mentargetkan CPL (soft skill dan hard skill serta kompetensi lainnya) untuk setiap pembahasan/pertemuannya. Aspek tersebut dapat membantu meningkatkan kualitas pembelajaran dalam mata kuliah masingmasing, sehingga perlu dirancang dengan tepat agar memacu belajar mahasiswa dan terjadi proses pembelajaran bermakna. Menurut Ausubel dalam Dahar (1996) 
mengungkapkan bahwa bahan pelajaran yang dipelajari harus "bermakna' (meaningfull). Belajar bermakna merupakan proses mengaitkan informasi atau materi baru dengan konsep-konsep yang telah ada dalam struktur kognitif. Dua prasyarat terjadinya belajar bermakna, yaitu : (1) materi yang akan dipelajari harus bermakna secara potensial, dan (2) anak yang akan belajar harus bertujuan belajar bermakna. Selain itu, kebermaknaan potensial materi pelajaran bergantung kepada dua faktor, yaitu : (1) materi itu harus memiliki kebermaknaan logis, dan (2) gagasan-gagasan yang relevan harus terdapat dalam struktur kognitif peserta didik. Terdapat tiga kebaikan dari belajar bermakna yaitu 1) informasi yang dipelajari secara bermakna lebih lama dapat diingat, 2) informasi yang dipelajari secara bermakna memudahkan proses belajar berikutnya untuk materi pelajaran yang mirip, dan 3) informasi yang dipelajari secara bermakna mempermudah belajar hal-hal yang mirip walaupun telah terjadi lupa.

Menurut Syachruddin (2016) bahwa kegiatan perkuliahan pada dasarnya ada 3 komponen utama yang perlu diperhatikan, yaitu: perencanaan, pelaksanaan dan evaluasi. Pemantauan pelaksanaan kegiatan perkuliahan dan pembelajaran untuk mengukur dampak dari proses perkuliahan atau pembelajaran yang diikuti dengan evaluasi untuk menentukan nilai terhadap sesuatu yang berkaitan dengan dunia pendidikan dan pengajaran. Hasil dari kegiatan pemantauan dapat dijadikan sebagai dasar untuk merencanakan langkahlangkah yang lebih baik dalam meningkatkan efektivitas dan efisiensi pelaksanaan perkuliahan sehingga kualitas pendidikan dan pengajaran dapat ditingkatkan. Efektivitas dan efisiensi kegiatan perkuliahan untuk masa yang akan datang perlu dilakukan monitoring pada administrasi, tenaga maupun dari segi proses serta alat penunjang lainnya, terutama pada kegiatan praktikum dan laboratorium agar manajemen pendidikan dan pengajaran dapat diperbaiki dan ditingkatkan agar kualitas mahasiswa dapat ditingkatkan.

Aly (2017) dalam penelitiannya mengungkapkan bahwa para dosen dapat menggunakan soft skills untuk mengembangkan karakter mahasiswa melalui kegiatan kemahasiswaan dengan menggunakan salah satu teori soft skills dan bentuk-bentuknya yang dikemukakan oleh Illah Sailah, baik yang bersifat personal, intra personal atau gabungan dari keduanya. Selain itu para dosen dapat menjadikan soft skills sebagai basis pembelajaran karakter di perguruan tinggi, yang terdiri atas tiga alternatif cara, yaitu melalui pembelajaran mata kuliah itu sendiri, melalui penggunaan metode perkuliahan dengan mengintegrasikannya ke dalam mata kuliah tertentu dan menjadikan dosen sebagai role 
model bagi para mahasiswa dimana proses pembelajarannya perlu diarahkan pada 2 aspek pembelajaran, yaitu tujuan dan materi yang berbasis soft skills.

\section{KESIMPULAN}

Keaktifan mahasiswa dalam perkuliahan dan Unit kegiatan Mahasiswa (UKM) sangat penting, karena dapat meningkatkan hard skills dan mengasah soft skills mahasiswa. Keaktifan mahasiswa tersebut merupakan rekam jejak mahasiswa calon guru selama mengikuti perkuliahan. Pengembangan soft skills pada mahasiswa dapat memaksimalkan kinerja selama mengikuti perkuliahan dan juga membantu dalam mencapai jenjang karir karena mempunyai keahlian khusus yang dimiliki sehingga lulusan perguruan tinggi mempunyai kompetensi dalam penguasaan dan penggunaan ilmu pengetahuan dan teknologi serta mampu untuk berkomunikasi, bekerja dalam tim, mandiri dan berpikir analitis.

\section{DAFTAR PUSTAKA}

Aly, Abdullah. (2017). Pengembangan Pembelajaran Karakter Berbasis Soft Skills Di Perguruan Tinggi. Ishraqi. Volume 1 No. 1. ISSN: 14125722. Universitas Muhammadiyah Surakarta (UMS)

Cahyono, Didik. (2012). Guru Abad 21. Diakses dari laman web tanggal 5 Februari 2016 dari https://areknerut.wordpress.com/2012/12/2 0/guru-abad-21-2/

Dahar, R.W. (1996). Teori-teori Belajar. Jakarta: Erlangga.
Herizon dan Wirda. F. (2012). Pengembangan Soft Skills Melalui Pendekatan Student Centre Learning Di Perguruan Tinggi. POLI BISNIS Vol 4, No 2 (2012) halaman. 101-112Ikhsania.

Anisa Amalia.

(2013).

Mahasiswa dan

Organisasi. Diakses dari laman web tanggal 4 Februari 2016 dari : http://www.kompasiana.com

Rahayu. E.L. ( 2013). Keterampilan Berkomunikasi Siswa. Diakses dari laman web tanggal 6 Februari 2016 dari http:// eprints.uny.ac.id18188/4/4

Rao. M.S. (2015). Step By Step To SoftSkills Training: How To Enhance Employability Skills In Students. Human Resource Management International Digest, Vol. 23 Issue: 6, pp.34-36, https://doi.org/10.1108/HRMID06-2015-0099

Rismansyah, Lukman. (2015). Perananan Soft skills Bagi Mahasiswa Yang Akan Bekerja Maupun Membuat Lapangan Pekerjaan Diakses dari laman web tanggal 6 Maret 2017 dari: http://characterbuildinglukman.blogspot.co .id/2015/05/perananan-soft-skills-bagimahasiswa.html

Setiawan, Budi., Supriyono. (2016). Pengembangan Media Pembelajaran Multimedia Dengan Powerpoint dan Wondershare Untuk Pengembangan Soft Skills Siswa bagi Guru SMP. Jurnal Ilmiah Saintikom, Sain dan computer ISSN : 1978-6603

Suharyanti, C. Murtini, W. Susilowati, W. (2015). Pengaruh Proses Pembelajaran dan Program Kerja Praktek Terhadap Pengembangan Soft Skills Mahasiswa. Jurnal Pendidikan Administrasi Perkantoran Vol 4, No 1.

Sulaiman, M. (2015). Meningkatkan Keterampilan Berbicara Melalui Metode Presentasi. Diakses dari laman web tanggal 5 Februari 2017 dari : https://prezi.com/xpqm1 icwlfu8/meningk atkan-keterampilanbebicara-melaluimetode- presentasi/

Syachruddin, A. R. (2016). Evaluasi Pendidikan Dan Pengajaran Melalui Pemantauan Proses Perkuliahan Pada FKIP Unram. Jurnal Ilmu Pendidikan Volume 21 No. 2.

Tohirin. (2007). Bimbingan dan konseling di sekolah dan madrasah (berbasis integrasi). Jakarta : Raja Grafindo Persada. 